\section{CYANINE CHEMISTRY}

\section{The Cyanine Dyes and Related Compounds}

By Frances M. Hamer. (The Chemistry of Heterocyclic Compounds: a Series of Monographs.) Pp. xxxvi +790 (New York and London: Interscience Publishers, Division of John Wiley and Sons, 1964.) $340 s$.

$7 \mathrm{HE}$ ability of certain dyes to make silver halide omulsions sensitive to light of wave-lengths longer than those to which they respond per se has made possible the more faithful photographic reproduction of scenes in black and white. Also, without sensitizers colour photography would have been unknown and all film speeds would have been severely limited since no energy derived from light of the longer wave-lengths could have been utilized. Noisy arc lamps in the film studio would certainly have handicapped the production of sound films - sensitizers made possible the change to the yellowor but silent filament lamps. Thus photography in many of its technical aspects has boen intimately connected, for the past 60 years, with sensitizers, and the useful sensitizers have almost invariably been selected from a class of dyes known generically as the cyanines. Dr. Frances M. Hamer brings out these points in the intoresting introduction to her volume in the Interscience series of monographs on heterocyclic compounds. She has been associated perhaps more than anyone else with the chemistry of the cyanines and it is therefore most appropriate that this monograph should be written by her.

With some important exceptions, notably in the merocyanine sories, characteristically, cyanine molecules comprise two heterocyclic nuclei, very often quinoline or benzothiazole, one of which bears a quaternized nitrogen atom, joined by an odd number of carbon atoms in such a way that the two nitrogen atoms of the heterocyclic residues are linked in a fully conjugated system. This volume is devoted almost entirely to the synthetic aspects of the subject. Dr. Hamor has collected together an onormous mass of information, culled mostly from the patent literature, and has classified it according to the type of cyanine and the basis of the methods of prepara. tion.

Nomenclature in the cyanine field has often been confusing in the past, and the systematic names of tho various classes can be rather cumbersome. Dr. Hamex has chosen to use semi-trivial names in the text but systematic names in the chapter titles. Thus the chapter devoted to "pentamethineyanines" includes sections on " 2,2 '-dicarbocyanines", and "thia-2'-dicarbocyanines". One can sympathize with the author in her dilemma and congratulate her on her solution.

The sheer bulk of material discussed has obviously made it impossible to include enough structural formula to make the text easily readable. For the most part only the structures of reaction products are given and it will be necessary for the reader himself to translate the names of intermediates and starting materials into structures. His task is not made easier by the labelling of formulae with the cumbersome Roman numerals or by crossreferencing to chapters and sections of chapters rather than to particular pages.

Dr. Hamor has obviously been handicapped by the particular nature of her subject which, boing closely connected with tochnology, is subject to trade secrecy. Thus the constitutions of particular sensitizers in present. day use are not disclosed. The patent literature, of groat importance in this field, is of little valuo in the assessment of the relative values of different products.

The sources of information also make it difficult to select the best method of preparation of a compound, although whenever possible the yield of product has been given.

This book will be invaluable to chemists about to work in the field of cyanine chemistry and will for many years be a standard work of reference. As with other monu. mental compilations, by the time it finally appeared in print the work recorded was already a few years old.

A. F. Crowther

\section{PLANT CHEMISTRY}

The Chemistry of Plant Processes

By Prof. C. P. Whittingham. (Methuen's Monographs on Biological Subjects.) Pp. 209. (London: Methuen and Co., Ltd., 1964.) 25s.

IN the words of Prof. C. P. Whittingham "this book attempts to present concisely a broad survey of plant physiology and biochemistry suitable for university students . . . who should have some basic knowledge of the physical sciences". There is little doubt that it succeeds admirably in these aims.

The first part, occupying slightly more than half the book, deals with cellular metabolism. Starting with a brief statement of the historical development and the nature of experimental botany, Prof. Whittingham then sets the modern scene with an outline of the fine structure of plant colls and the methods of studying organelles and their functions. This leads naturally to a chapter on enzymes as an introduction to the metabolic meat of the book, the four chapters on fermentation and respiration, energetics of respiration and biological syntheses, photosynthesis and nitrogen metabolism respectively. Together these four chapters make up nearly half the book and are masterpieces of conciseness and clarity. Prof. Whittingham has been absolutely ruthless in the elimination of all unnecessary frills and verbiage, and the result is a highly condensed and, at the same time, completely thorough and readable portrayal of the present-day scene. The reader is brought right up to date on recent advances although there is no neglect of the classical foundations that have made these advances possible.

The second part of the book is entitled "Plant Processes" by which is meant phenomena of plant function which are not susceptible to the same dissection into discrete chemical processes as those of the first part. 'The author' includes the osmotic relations of the cell, the water rela. tions of the whole plant, the transport of solutes and growth. The first of these chapters on osmotic phenomena is as excellent as those preceding it, but thence the quality declines somewhat. Possibly because the relevant phenomena cannot yet be examined with comparable precision, possibly because the systems involved are more complex and difficult to define, the author has not been able to weld the selected material into such a satisfying story. This is particularly true of the chapter on growth, which is incomplete and a little disjointed; but this might have been cured by a more generous allocation of space, since even the masterly conciseness characterizing the first part of the book could not be expected to create a balanced statement of such a complex subject as plant growth in a mere twenty pages.

The book closes with an eleven-page appendix on the chemistry of the constituents of living organisms. This could with profit have been longer.

As was his intention, the author has produced an excellent framework on which the student of plantphysiology and biochemistry can baso his further reading. For this there are 167 titles in a list of references in which the inclusion of a few additional critical reviow articles would have been an improvement.

In spite of these minor criticisms the book excellently fills a very real need and can be strongly recommended to all advanced students of botany.

L. J. AODes 